\title{
All arthroscopic stabilization of acute acromioclavicular joint dislocation with fiberwire and endobutton system
}

\author{
Marco Spoliti ${ }^{1}$ \\ Mauro De Cupis ${ }^{2}$ \\ Alessio Giai Via ${ }^{2}$ \\ Francesco Oliva ${ }^{2}$
}

1 Department of Orthopaedics and Traumatology, San Camillo-Forlanini Hospital, Rome, Italy

2 Department of Orthopaedics and Traumatology, University of Rome "Tor Vergata" School of Medicine, Rome, Italy

Corresponding author:

Alessio Giai Via

Department of Orthopaedics and Traumatology, University of Rome "Tor Vergata"

School of Medicine

Viale Oxford 81

00133 Rome, Italy

E-mail: alessiogiaivia@hotmail.it

\section{Summary}

Introduction: acromioclavicular (AC) joint dislocation is common in athletes and in contact sports and about $9 \%$ of shoulder injuries involves this joint. The majority of these AC lesions can be successfully treated conservatively but high grade dislocation and some cases of type III dislocation need a surgical treatment. Many different operative techniques have been described over the years. The purpose of this study is to evaluate the results of arthroscopic stabilization of AC joint dislocation with TightRope ${ }^{\circledR}$ system.

Materials and methods: nineteen patients with acute AC dislocation were treated by arthroscopic fixation with TightRope ${ }^{\circledR}$ system. Any associated lesions were repaired. All patients were assessed before surgery (T0), at 3 months (T1), at 6 months (T2) and at 1 year after the surgery (T3) using a visual analogic scale (VAS) and Constant-Murley Score (CMS). All patients were evaluated with X-ray. Results: six AC-joint dislocations involved the right shoulder and thirteen the left shoulder. Ten were type III dislocation, three were type IV and six were type $V$ dislocation. We found a statistically significant reduction of pain $(p<0.01)$ at $T 1$ compared to the pretreatment scores. The CMS measures showed an improvement between T1,
T2 and T3, but the difference was statistically significant only between T1 and T3 $(p=0.017)$. The postoperative X-Ray of the shoulder showed a good reduction of the AC joint dislocation. We had 1 case of recurrence and 2 cases of loss of intraoperative reduction.

Conclusion: arthroscopic technique for acute AC joint dislocations with the use of the TightRope ${ }^{\circledR}$ device is minimally invasive and it allows an anatomic restoration of the joint. It is a safe and effective procedure ensuring stable $A C$ joint reconstruction and good cosmetic results.

KEY WORDS: acromioclavicular joint dislocation, arthroscopic reconstruction, AC joint separation, endobutton system.

\section{Introduction}

Approximately $9 \%$ of shoulder injuries involve damage to the acromioclavicular (AC) joint ${ }^{1}$. AC-joint dislocations are common in athletes, especially in contact sports or after fall while skiing or cycling $^{2}$, and after motorcycle accidents ${ }^{3}$. AC-joint injuries have been classified into 6 types by Rockwood and Green ${ }^{4}$ (Fig. 1). Type III is classified as a superior displacement of the lateral end of the clavicle of one clavicular diameter or $1 \mathrm{~cm}$ on the anteroposterior radiograph ${ }^{5}$. The majority of these AC lesions can be successfully treated without surgery, particularly type I and II while operative treatment is indicated for Rockwood type IV, V, and VI injuries ${ }^{3,5}$. Treatment of type III AC-joint separation is still debated in literature. Although evidence supporting non-operative treatment has been provided by a previous metaanalysis 6 , more recent study showed significant better functional outcome following operative compared to non-operative management ${ }^{7}$, and some authors advocate surgical reconstruction for patients with physically demanding occupations or sporting interests $^{5}$. Acute high-grade AC-joint separations may be associated with intra-articular lesions. Concomitant SLAP-lesions, PASTA lesions, rotator cuff tears (RCTs) and subscapularis tendon tears have been reported in literature 8,9 .

A variety of operative techniques have been developed over the years. They can be divided into 2 groups focusing on the ligament healing or on the ligament reconstruction. The first techniques try to maintain the clavicle-coracoid relationship in a re- 


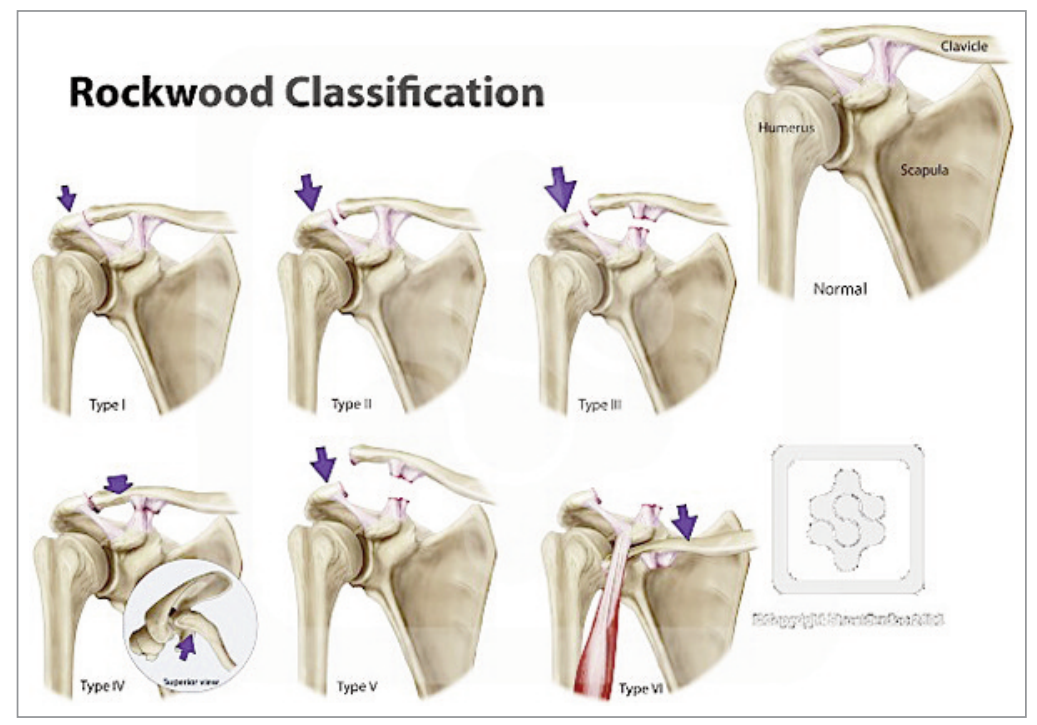

Figure 1. Rockwood and Green classification of acromioclavicular (AC) joint dislocations.

duced position in order to allow primary healing of the CC ligaments, but they are not indicated for chronic dislocations. Instead the second group techniques focuses on CC ligament reconstruction. They are indicated in high-grade dislocations or in chronic injuries, and the most popular and widely used technique was originally described by Weaver and Dunn in $1972^{10}$. AC-joint stabilization can also be performed through both open or arthroscopically assisted techniques. Several arthroscopic techniques have been described and recommended for the treatment of $A C$ joint dislocation ${ }^{11-13}$.

The aim of this study was to evaluate retrospectively the results of arthroscopic stabilization of $A C$ joint dislocation with TightRope ${ }^{\circledR}$ system.

\section{Materials and methods}

We reviewed retrospectively 19 patients (16 men, 3 women) who underwent arthroscopic stabilization of acute AC joint dislocation with TightRope ${ }^{\circledR}$ system, (Arthrex, Naples, Florida, USA) from 2008 to 2011. All procedures were performed after the patients had signed a written consent and after approval by the local Internal Review Board (IRB). This research has been conducted ethically according to international standards and as required by the journal ${ }^{14}$.

\section{Inclusion and exclusion criteria}

Inclusion criteria were clinical and radiographic evidence of type III AC joint separation or greater, acute injury (6 weeks), patients age younger than 35 years, active athlete or patients with high functional demands. Exclusion criteria were type I and II AC joint separation, chronic injury (AC joint separation greater than 6 weeks), patients older than 35 , or patients with low shoulder functional demands or no sporting interest.

\section{Clinical and radiological evaluation}

Clinical evaluation included inspection (swelling, hematoma), palpation (painful crepitation, elevated and/or blocked and luxated lateral clavicle) and typically a painful limitation of range of motion.

Standard AP X-ray of the shoulder was performed at emergency in all patient. A preoperative CT of the shoulder was performed in order to classify the le$\operatorname{sion}^{15}$ (Fig. 2). All patient had X-ray control of the shoulder in AP and Zanca view after surgery, at 30 days and at 3 months.

\section{Outcome measures}

All the patients were assessed before surgery (T0), at 3 months (T1), at 6 months (T2) and at 1 year after the surgery (T3). The Visual Analog Scale ${ }^{16}$ (VAS) score were recorded at T0 and T1. VAS score is a subjective measure of pain, ranges from 0 (no pain) to 10 (worst pain). It was not recorded at TO because of painful functional limitation after the injury. The Constant-Murley Score $^{17}$ (CMS) has been evaluated at T1, T2 and T3. It is based on four variables that are used to assess shoulder function considering both subjective (sleep, work, recreation/sport) and objective variables (range of motion and strength). The maximum overall score is thus 100 which indicates a normal shoulder.

\section{Intervention}

We performed a reduction of $\mathrm{AC}$-joint and an arthroscopic stabilization of CC ligaments in all patients for acute AC-joint dislocations. We used a single TightRope ${ }^{\circledR}$ device for the $\mathrm{CC}$ repair. It is a double metallic button with four FiberWire strands (Arthrex, Naples, FL).

The patient was positioned in a standard beachchair. We performed three different portals, the 


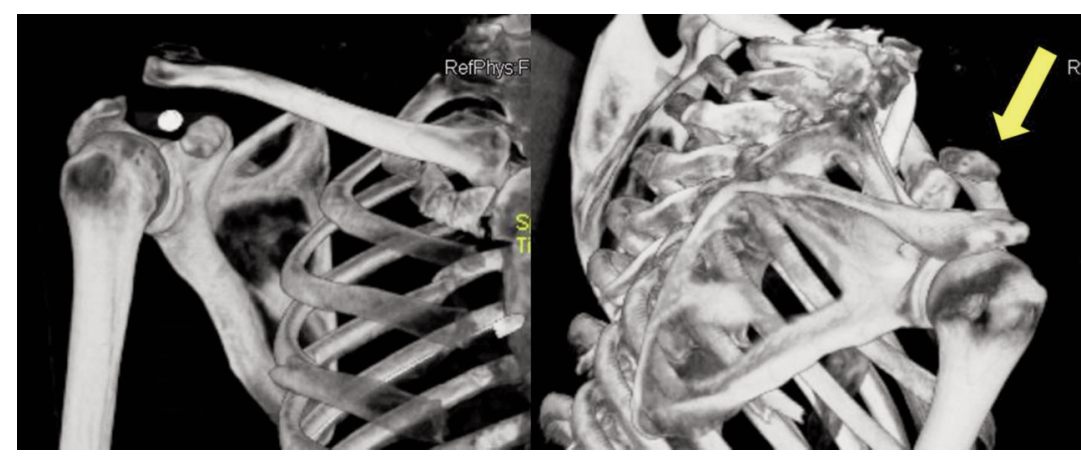

Figure 2. Type IV AC joint

dislocation.

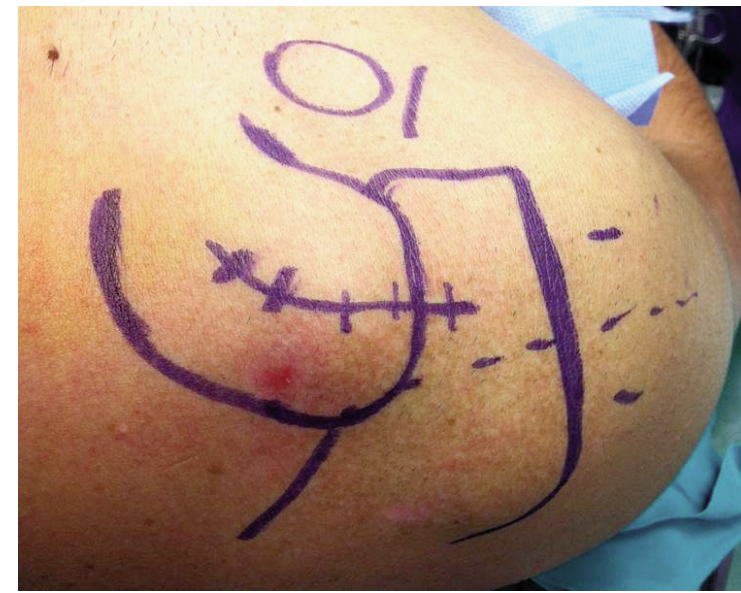

Figure 3. The arthroscopic portals.

standard posterior soft spot portal, an anterosuperior portal and an anterior-inferior (Mattews' portal) (Fig. 3). An arthroscopic look of gleno-humeral joint was performed first. Associated lesions such as SLAP lesions or supraspinatus tendon tears were diagnosed and repaired with one or more bonny anchors. Tears of the AC joint capsule and interposition of soft tissue into the AC joint were identified through a mini-open access over the AC joint. The $A C$ joint dislocation was reduced and it was temporary stabilized with a Kirschner wire under fluoroscopic guide. The undersurface of the coracoid was cleaned from all soft tissue with the radiofrequency device having a full view at the coracoid arc. The tip of the TightRope ${ }^{\circledR}$ aimer was placed at the inferior surface of the coracoid arc through the anterior portal. We used a $4 \mathrm{~mm}$ cannulated drill to create a tunnel through the clavicle and coracoid. The TightRope ${ }^{\circledR}$ was pulled through the clavicle and coracoid. Once the button was flipped, traction was applied and the sutures at the round clavicle button was tied under direct visualization. Than the K-wire was removed and an intraoperative fluoroscopic control was performed.

\section{Postoperative treatment}

The affected shoulder was immobilized in a shoulder brace in a neutral position for 6 weeks. At 4 weeks the patient stated a gentle passive assisted mobilization and active mobilization was permitted at 6 weeks after the surgery. NSAIDs have been used to control pain. The patients are not allowed to carry any weight with the arm for 6 months.

\section{Statistical Analysis}

Statistical significance was determined by one-way analysis of variance (ANOVA, Tukey's Range Test). For all statistical tests, the level of significance was set to $p<0.05$.

\section{Results}

Nineteen patients meet the inclusion criteria during the period study. The mean age was 33 years (range 23-42 y) (SD 4.77). No patient was a professional athlete, but most of them were amateur athletes. The most common mechanism of injury was motorcycle accident $(47 \%$ of cases) (Tab. 1$)$.

Six AC-joint dislocations involved the right shoulder and thirteen the left shoulder. In $42 \%$ of the patients the dislocation affected the dominant shoulder.

According to Rockwood and Green classification ten were type III dislocation, three were type IV and six were type $\mathrm{V}$ dislocation. No patients came to our observation showing a type $\mathrm{VI}$ dislocation. The average onset from trauma to arthroscopic repair was 10 days (range 7-21 days). We found associated lesions in $35.3 \%$ of patients (Tab. 2).

Pretreatment mean VAS score was 8.47 (SD 1.02). We found a reduction of pain at T1 compared to the pretreatment scores. The mean difference was 6,368, and the ANOVA test applied between T0 and T1 VAS score showed a statistically significant reduction of

Table 1. Mechanism of injury.

\begin{tabular}{ll}
\hline Mechanism of injury & Number of cases \\
\hline Motorcycle accident & 9 cases \\
Soccer injury & 2 cases \\
Rugby injury & 1 case \\
Ice skating injury & 1 case \\
Bicycle injury & 2 cases \\
Others & 4 cases \\
\hline
\end{tabular}


pain $(p<0.01)$. The CMS measures showed an improvement between T1, T2 and T3, but the difference was statistically significant only between T1 and T3 $(p=0.017)$. Patients data and the results of VAS score and CMS are reported in Tables 2 and 3 .

The postoperative X-Ray of the shoulder showed a good reduction of the AC joint dislocation (Fig. 4).

We had 1 case of recurrence and 2 cases of loss of intraoperative reduction. We did not experienced any case of intraoperative complications nor infections.

\section{Discussion}

AC joint dislocation is a common sports-related injury, it occurs more often in men than in women and

Table 2. Patients data.

\begin{tabular}{|c|c|c|c|c|c|c|c|c|c|c|}
\hline n. & Age & $\begin{array}{l}\text { Types } \\
\text { of AC } \\
\text { dislocation }\end{array}$ & $\begin{array}{l}\text { Time } \\
\text { before } \\
\text { surgery }\end{array}$ & $\begin{array}{l}\text { Associated } \\
\text { lesions }\end{array}$ & $\begin{array}{l}\text { VAS } \\
\text { Score } \\
\text { (T0) }\end{array}$ & $\begin{array}{l}\text { VAS } \\
\text { Score } \\
\text { (T1) }\end{array}$ & $\begin{array}{l}\text { CONSTANT } \\
\text { Score } \\
(\mathrm{T} 1)\end{array}$ & $\begin{array}{l}\text { CONSTANT } \\
\text { Score } \\
\text { (T2) }\end{array}$ & $\begin{array}{l}\text { CONSTANT } \\
\text { Score } \\
\text { (T3) }\end{array}$ & Recurrence \\
\hline 1 & 33 & V & 7 & - & 9 & 3 & 88 & 90 & 65 & - \\
\hline 2 & 42 & IV & 21 & - & 6 & 3 & 90 & 95 & 64 & Type III \\
\hline 3 & 36 & III & 13 & - & 8 & 2 & 90 & 88 & 85 & - \\
\hline 4 & 25 & IV & 10 & - & 7 & 4 & 75 & 80 & 78 & $\begin{array}{l}\text { loss of } \\
\text { reduction }\end{array}$ \\
\hline 5 & 35 & IV & 8 & - & 9 & 1 & 85 & 95 & 98 & - \\
\hline 6 & 26 & IV & 12 & SLAP & 7 & 1 & 80 & 90 & 97 & - \\
\hline 7 & 23 & IV & 13 & SLAP & 10 & 2 & 85 & 92 & 98 & - \\
\hline 8 & 35 & III & 8 & - & 7 & 3 & 85 & 85 & 85 & - \\
\hline 9 & 39 & IV & 10 & - & 9 & 2 & 86 & 90 & 95 & - \\
\hline 10 & 35 & IV & 9 & - & 7 & 0 & 85 & 90 & 97 & - \\
\hline 11 & 33 & III & 12 & $\mathrm{RCT}$ & 8 & 6 & 74 & 85 & 95 & - \\
\hline 12 & 27 & III & 8 & - & 9 & 1 & 80 & 95 & 98 & - \\
\hline 13 & 37 & V & 9 & SLAP & 10 & 2 & 85 & 85 & 85 & $\begin{array}{l}\text { loss of } \\
\text { reduction }\end{array}$ \\
\hline 14 & 38 & IV & 8 & SLAP & 8 & 1 & 80 & 85 & 97 & - \\
\hline 15 & 30 & III & 7 & SLAP & 9 & 1 & 86 & 88 & 98 & - \\
\hline 16 & 39 & IV & 9 & - & 9 & 0 & 88 & 90 & 95 & - \\
\hline 17 & 29 & III & 7 & SLAP & 10 & 0 & 80 & 98 & 99 & - \\
\hline 18 & 26 & V & 11 & - & 9 & 6 & 72 & 80 & 82 & - \\
\hline 19 & 40 & IV & 9 & - & 8 & 2 & 85 & 90 & 94 & - \\
\hline
\end{tabular}

Table 3. The results of VAS and CONSTANT scores.

\begin{tabular}{llllllll}
\hline & \multicolumn{3}{c}{ VAS Score } & & \multicolumn{2}{c}{ CONSTANT Score } \\
\cline { 2 - 3 } Follow-up & Mean difference & $\mathrm{SD}$ & ANOVA test & & Mean difference & SD & ANOVA test \\
\hline T0-T1 & 6.368 & 1.02 & $\mathrm{p}=0.0001$ & & - & - \\
T1-T2 & - & - & - & - & & 5.73 & $\mathrm{p}=3.58$ \\
T2-T3 & - & - & - & & 0.73 & 10.9 & $\mathrm{P}=0.267$ \\
T1-T3 & - & - & - & 6.52 & 12.8 & $\mathrm{P}=0.0175$ \\
\hline
\end{tabular}

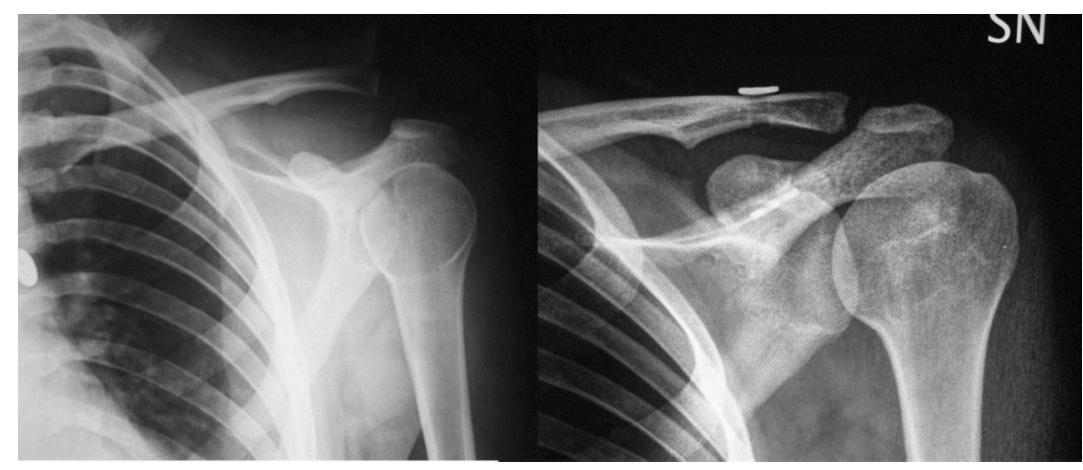


the overall incidence in the United States is estimated 4/100.000 people ${ }^{18}$.

Treatment options vary according to the severity of the injury. Type-I and II are widely regarded as best managed conservatively, while surgery is indicated for Type-IV, Type-V and VI dislocations in order to avoid unsatisfactory results like painful joint and significant loss of strength of the affected upper limb. Treatment of Type-III injuries is still controversial. Previous systematic review did not support operative procedure for Rockwood Type III injury ${ }^{6}$ because patients often regain excellent clinical results and shoulder function, although the risk of chronic instability and pain ${ }^{19}$. But recently, thanks to the improvement of surgical techniques, surgical results improved compared to the historically poor results of fixation with K-wires, and some authors suggested that surgical reconstruction should be advocated for those patients who have physically demanding occupations or sporting interests ${ }^{7}$. A recent systematic review reported that operative management of Type III $A C$ joint dislocation provided a significantly better Constant score and better cosmetic results compared to non-operative ${ }^{5}$.

Comparing to standard open procedures, all arthroscopic AC joint repair seems to have several advantages. Standard procedures for AC joint reconstruction need a large exposure of the coracoid process. Detachment of part of the deltoid insertion and extensive soft tissue dissection can be dangerous for neurovascular structures and in some cases visibility around the coracoid process may be still suboptimal. For this reason interest in the use of arthroscopically assisted CC ligament repair is increasing; this technique offers smaller incisions, minimal soft tissue dissection and superior visualization of the coracoid base. AC joint separations may be associated with concomitant intra-articular lesions which often could remain undetected as they are masked by the painful AC joint injury. Intra-articular lesions, such as SLAP-lesions, PASTA lesions and RCTs have been reported from 15 to $18 \%$ of patients affected by AC joint dislocation ${ }^{13,20}$ and they could be the cause of persistent shoulder pain after an otherwise successful AC joint repair. Therefore an arthroscopic approach allows to diagnose and treat associated intra-articular pathologies. Literature showed that surgical techniques that employ rigid form of fixation have resulted in failures, because the $\mathrm{AC}$ joint is not a rigid joint ${ }^{21}$. In fact with full overhead elevation the clavicle rises by up to 35 degrees and rotates on its long axis by 45 degrees, and with adduction and extension it displaces by up to 35 degrees anteriorly and posteriorly. Stabilization of AC joint dislocation with TightRope ${ }^{\circledR}$ system allows a non-rigid fixation of the $A C$ joint with an anatomic reduction and restoration of normal arthrokinematics.

Several arthroscopic techniques have been described and recommended for the treatment of $A C$ joint dislocation. Wolf et al. ${ }^{13}$ in 2001 first described a technique using an autologous tendon transfer (semitendinosus graft) in order to restore the torn coracoclavicular ligaments. Lafosse ${ }^{22}$ described allarthroscopic technique for coracoclavicular ligament reconstruction with coracoacromial ligament transfer. In 2008 Salzmann et al. ${ }^{23}$ used two tight rope system for arthroscopic repair of CC ligaments. De Berardino et al. ${ }^{24}$ reported good results in 10 patients treated with arthroscopic stabilization of $A C$ joint dislocation using the AC graftrope system. All patients returned to their normal pre-injury level of activity.

We prefer TightRope ${ }^{\circledR}$ system in order do not change the normal anatomy of the clavicle-coraco-acromial complex. The theoretical strength of the fixation we can obtain is superior than the original strength of the CC ligaments. Cadaveric studies showed that the ultimate load to failure of AC-joint was about 500-700 $\mathrm{N}^{18}$ while the load to failure of button and FiberWire system is more than $1400 \mathrm{~N}^{25}$. Isolated reconstruction of the CC ligaments using a single clavicular tunnel reconstruction technique resulted in a high load to failure for superior translation, which is equal to the native stability, and greater stability when compared with the modified Weaver-Dunn procedure ${ }^{26}$. Furthermore, the use of 2 clavicular tunnels in a modified technique did not result in significant improvement for the measured variables, but it is technically more demanding and it may increase the risk of clavicular or coracoid fractures ${ }^{26}$.

Finally there is no need to remove the implant thanks to the very low profile.

We had one cases of failure (type 3 separation) and one case of loss of intraoperative reduction (type 2 separation). In a third case the button sank through the clavicle with a partial loss of reduction. These may be due to lack of experience in this new arthroscopic technique. In particular, in the case of failure the tunnel through the clavicle and coracoid base has been created without the previous temporary stabilization of the joint with a K-wire. We think it is important to create tunnels in correct position to avoid widening tunnel and sinking of the proximal button (Fig. 5). Another advantage of this approach is that in case of failure a second reconstruction with tendon graft or standard open techniques is possible.

This study has several limitations. First the small number of patients and the lack of a control group. The short-term follow-up is also a limitation of our study, but considering the small number of patients, we preferred not risk losing patients at a longer follow-up. The short-term follow-up also prevents us from determining the relapse rate. Furthermore the Constant score is a general shoulder clinical evaluation test and not specific for AC joint. This theoretically may have affected the findings. Finally the lacking of statistical power due to the small sample size is another limitation of our study whereby we do not claim which our conclusions can be extended to the general population. 


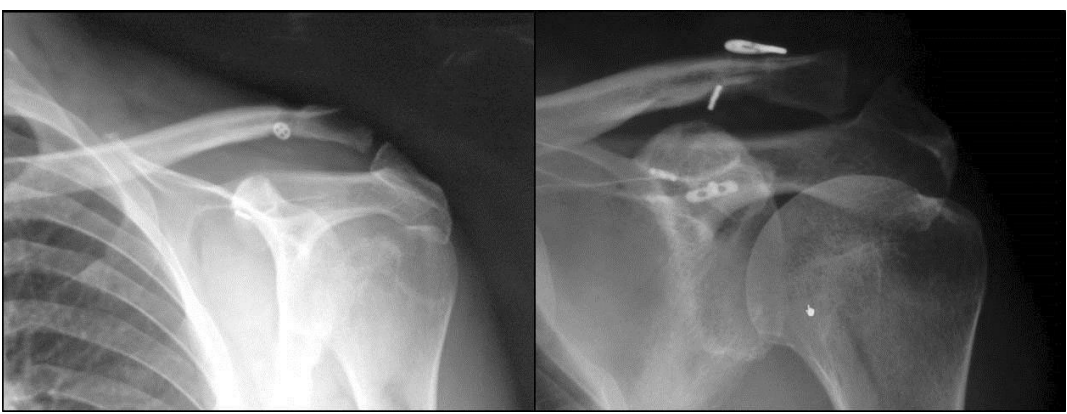

Figure 5. Sinking of the proximal button through the clavicle and loss of reduction.

\section{Conclusion}

Arthroscopic technique for acute $A C$ joint dislocations with the use of the TightRope ${ }^{\circledR}$ device is minimally invasive and it allows an anatomic restoration of the joint. We believe it is a safe and effective procedure, and a valid option to stabilize the $A C$ joint with a good cosmetic results. We advocate arthroscopic stabilization for type III dislocations in young patients, athletes, active and handworker patients.

\section{Conflict of interests}

The authors declare no conflict of interests.

\section{References}

1. Crenshaw A. Fractures of the shoulder girdle, arm and forearm. St. Louis: Mosby. 1992.

2. Boileau P, Old J, Gastaud O, Brassart N, Roussanne Y. Allarthroscopic Weaver-Dunn-Chuinard procedure with doublebutton fixation for chronic acromioclavicular joint dislocation. Arthroscopy. 2010;26:149-160.

3. Mazzocca AD, Arciero RA, Bicos J. Evaluation and treatment of acromioclavicular joint injuries. Am J Sports Med. 2007;35: 316-329.

4. Rockwood CA Jr, Williams GR, Young CD. Injuries to the acromioclavicular joint. In: Rockwood CA Jr et al. Fractures in adult. Philadelphia: Lippincott. 1996:1341-1431.

5. Smith TO, Chester R, Pearse EO, Hing CB. Operative versus non-operative management following Rockwood grade III acromioclavicular separation: a meta-analysis of the current evidence base. J Orthop Traumatol. 2011;12:19-27.

6. Phillips AM, Smart C, Groom AF. Acromioclavicular dislocation. Conservative or surgical therapy. Clin Orthop Relat Res. 1998;353:10-17.

7. Gstettner C, Tauber M, Hitzl W, Resch H. Rockwood type III acromioclavicular dislocation: surgical versus conservative treatment. J Shoulder Elbow Surg. 2008;17:220-225.

8. Elser F, Chernchujit B, Ansah P, Imhoff AB. A new minimally invasive arthroscopic technique for reconstruction of the acromioclavicular joint. Unfallchirurg. 2005;108:645-649.

9. Pauly S, Gerhardt C, Haas NH, Scheibel M. Prevalence of concomitant intraarticular lesions in patients treated operatively for high-grade acromioclavicular joint separations. Knee Surg Sports Traumatol Arthrosc. 2009;17:513-517.

10. Weaver JK, Dunn HK. Treatment of acromioclavicular injuries, especially complete acromioclavicular separation. J Bone Joint Surg Am. 1972;54:1187-1194.

11. Baumgarten KM, Altchek DW, Cordasco FA. Arthroscopically assisted acromioclavicular joint reconstruction. Arthroscopy. 2006;22:228

12. Chernchujit B, Tischer T, Imhoff AB. Arthroscopic reconstruction of the acromioclavicular joint disruption: surgical technique and preliminary results. Arch Orthop Trauma Surg. 2006;126:575-581.

13. Wolf EM, Pennington WT. Arthroscopic reconstruction for acromioclavicular joint dislocation. Arthroscopy. 2001;17:558563.

14. Padulo J, Oliva F, Frizziero A, Maffulli N. Muscles, Ligaments and Tendons Journal. Basic principles and recommendations in clinical and field science research. MLTJ. 2013:4:250-252.

15. Kim AC, Matcuk G, Patel D, et al. Acromioclavicular joint injuries and reconstructions: a review of expected imaging findings and potential complications. Emerg Radiol. 2012;19:399-413.

16. DeLoach LJ, Higgins MS, Caplan AB, Stiff JL. The visual analog scale in the immediate postoperative period: intrasubject variability and correlation with a numeric scale. Anesthesia \& Analgesia. 1998;86:102-106.

17. Yian EH, Ramappa AJ, Arneberg O, Gerber C. The constant score in normal shoulders. J Shoulder Elbow Surg. 2005;14; 128-133.

18. Costic RS, Labriola JE, Rodosky MW, Debski RE. Biomechanical Rationale for development of anatomical reconstructions of coracoclavicular ligaments after complete acromioclavicular joint dislocations. Am J Sports Med. 2004;32:1929-1936.

19. Calvo E, Lopez-Franco M, Arribas IM. Clinical and radiological outcomes of surgical and conservative treatment of type III acromioclavicular joint injury. J Shoulder Elbow Surg. 2006;15: 300-305.

20. Tischer T, Salzmann GM, El-Azab H, Vogt S, Imhoff AB. Incidence of associated injuries with acute acromioclavicular joint dislocations types III through V. Am J Sports Med. 2009;37:136-139.

21. Mazzocca AD, Santangelo SA, Johnson ST, Rios CG, Dumonski ML, Arciero RA. A biomechanical evaluation of an anatomical coracoclavicular ligament reconstruction. Am J Sports Med. 2006;34:236-246.

22. Lafosse L, Baier GP, Leuzinger J. Arthroscopic treatment of acute and chronic acromioclavicular joint dislocation. Arthroscopy. 2005;2:1017.

23. Salzmann GM, Walz L, Schoettle PB, Imhoff AB. Arthroscopic anatomical reconstruction of the acromioclavicular joint. Acta Orthop Belg. 2008;74:397-400.

24. DeBerardino TM, Pensak MJ, Ferreira J, Mazzocca AD. Arthroscopic stabilization of acromioclavicular joint dislocation using the AC graftrope system. J Shoulder Elbow Surg. 2010;19:47-52.

25. Costic RS, Vangura A Jr, Fenwick JA, Rodosky MW, Debski RE. Viscoelastic behavior and structural properties of the coracoclavicular ligaments. Scand J Med Sci Sports. 2003;13:305-310.

26. Beitzel K, Obopilwe E, Chowaniec DM, et al. Biomechanical comparison of arthroscopic repairs for acromioclavicular joint instability: suture button systems without biological augmentation. Am J Sports Med. 2011;39:2218-2225. 